\title{
How the Education Community Perceives Cyberbullying: a Comparison of Students, Teachers and Families
}

\author{
Pablo Bautista Alcaine $(1)$ and Eva Vicente Sánchez 10 \\ Departamento de Psicología y Sociología, Universidad de Zaragoza, Spain
}

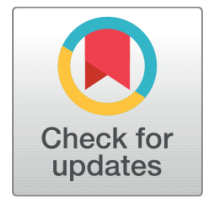

Received 2020-02-13

Revised 2020-03-10

Accepted 2020-05-11

Published 2020-07-15

\section{Corresponding Author}

Pablo Bautista Alcaine,

pbautista@unizar.es

Universidad de Zaragoza, Departamento de Psicología y Sociología, Facultad de Educación, Calle Pedro Cerbuna, 12, 50009, Zaragoza, Spain

DOI https://doi.org/10.7821/ naer.2020.7.554

Pages: 216-230

Distributed under

Creative Commons CC BY 4.0

Copyright: (C) The Author(s)

\section{ABSTRACT}

This study aims to find out how the groups that form the education community (students, teachers, families) differ in terms of the various characteristics surrounding the cyberbullying phenomenon. To do this, we conducted research using a selective correlational and cross-sectional design to analyze relationships and differences among variables: defining cyberbullying, typology, involved roles, possible causes and coping strategies in the different groups. The study recruited 116 participants as follows: $51 \%$ were year-6 Primary Education students; $29 \%$ were students' family members; $20 \%$ were school teachers. We collected data through an ad hoc questionnaire that a group of experts had previously validated. The results of the data analysis showed that significant differences appeared in terms of: how typologies were perceived; the importance of roles; coping strategies for cyberbullying.

\section{Keywords CYBERBULLYING, PERCEPTION, STUDENTS, TEACHERS, FAMILY}

\section{INTRODUCTION}

Cyberbullying is defined as aggressive and intentional action repeatedly performed via computers, mobiles and other electronic devices by a group or an individual over time against a victim who cannot easily defend him/herself (Patchin \& Hinduja, 2006, 2015; Smith et al., 2008). Whoever performs this action can do so at anytime, anywhere, but must have access to the Internet, have a device to on which to perform it, and have acquired technological skills and competences (García-Fernández, Romera-Félix, \& Ortega-Ruiz, 2016) .

For Ortega-Ruiz and Zych (2016), cyberbullying undoubtedly begins in real-world social life before moving to cybernetic social life and remaining in social networks. However, Patchin and Hinduja (2015), and Thomas, Connor, and Scott (2015), indicate that identifying cyberbullying is no easy task because measuring factors of reiteration, abusing power and intentionality can be complex.

Possible cyberbullying typologies constantly change because social networks and cyber communities advance as technology progresses (Menesini, Nocentini, \& Calussi, 2011).

\section{OPEN ACCESS}


Research by Kowalski and Limber (2007) and Smith et al. (2008) first categorised cyberbullying types in accordance with the instruments perpetrators employ: telephone calls, text messages, emails, images or videos, instant messaging, network or chat.

Lucas-Molina, Pérez-Albéniz, and Giménez-Dasí (2016) and von Marées and Petermann (2012) reflect that the following forms of cyberbullying are the most widespread: social exclusion (not allowing the victim to participate in a social network), denigration (false information or spreading rumors about the victim to harm him/her), harassment (causing offence using messages), impersonating identity (pretending to be the person in social networks to harm his/her image), violating identity (disseminating the victim's images or secrets without his/her consent), persecution (similar to harassment, but characterized by perseverance) and happy slapping (recording physical aggression against the victim and disseminating it).

The cyberbullying roles we may encounter are similar to those of conventional bullying identified by Olweus (1993): bully (who performs the bullying action), victim (who is bullied) and spectators. Sánchez and Cerezo (2011) specify the spectator role by indicating three possibilities: (a) non-involved spectator, who does not get involved, but is aware of the situation; (b) possible defender spectator, who does nothing, despite not agreeing with the situation; (c) defender spectator, who helps the victim. Additionally, the victim-provoker role has been identified as (s)he who plays both roles (Cerezo, 2009).

However, compared with cyberbullying, the bully's power over the victim is stronger owing to the typical characteristics of the phenomenon (Patchin \& Hinduja, 2015; Smith et al., 2008). Thomas et al. (2015) mention that, despite the roles being the same, the interaction between them and the means by which the phenomenon takes place make the imbalance of power and reiteration hard to explain.

Cowie (2013) indicates that cyberbullying victims, like conventional bullying victims, suffer psychological-type problems, such as depression, high levels of social anxiety and low self-esteem, which all directly lead to poor academic performance. Along these lines, Schenk and Fremouw (2012) add that cyberbullying victims may also suffer frustration, stress, rage, problems concentrating and sadness and with a low percentage, ideas of suicide.

Many coping strategies can be put into practice when facing cyberbulling, but they are not all equally effective. Caba and López (2013) classified strategies to face cyberbullying into two types: positive and negative. Positive strategies imply using dialog-linked assertive strategies with bullies or seeking help from the community. Negative strategies include taking a passive attitude toward cyberbullying (keeping silent, ignoring aggression, etc.) or negative reciprocity to return the cyberbullying action, regardless of it being virtual or physical.

Giménez-Gualdo (2015) describes how passive technological strategies (closing accounts, disconnecting, recording conversations, restricting ICT use, deleting conversations, blocking the bully, etc.) have become more important and more frequent than proactive technologies (Smith et al., 2008). This author also points out that sharing and making bullying situations public is more relevant for youths than communicating this to 
parents or teachers.

von Marées and Petermann (2012), Undheim, Wallander, and Sund (2016) and Sittichai and Smith (2018) state that the students involved in bullying and cyberbullying should receive training in effective coping strategies to overcome these situations. Lazarus (1993) defined these coping strategies as someone's behavioral and cognitive skills used to overcome an internal or external stress situation. Chan and Wong (2017) stress that the students who exhibit more self-esteem, empathy, prosocial behavior, good cohesion with family and at school, and who have positive experiences at school tend to put into practice adaptive coping strategies (e.g., seeking help from their family members, friends or teachers), while those who use maladaptive strategies (e.g., avoiding others, insulting others, not seeking support) tend to obtain poor results for these variables.

\subsection{Perception of cyberbulling of the different people involved (students, teachers, families)}

Compton, Campbell, and Mergler (2014) investigated how teachers, parents and students perceived cyberbullying. Parents and students only perceived the power imbalance characteristic of the phenomenon, and ignored both reiteration and intentionality; teachers ignored the above-cited characteristic, and considered that reiteration and intentionality were fundamental to harming victims in order to have fun or because of boredom. Teachers believed that cyberbullying may be simpler to perform due to its avoidance of face-to-face encounters and its anonymity allowing escape from punishment. A study by Mudhovozi (2015) indicated, surprisingly, that no teacher specified that cyberbullying actually existed or took it to be a form of possible harassment.

Compton et al. (2014) stressed that families believed that avoiding relationships, remaining anonymous, power, having fun and the ease with which cyberbullying can be performed were the main factors leading cyberbullies to harass their victim. Further to this finding, Cooper and Nickerson (2013) added that parents did not tend to seek out those cyberbullying situations that took place outside school, and denied seeing possible cyberbullying actions.

According to Compton et al. (2014), avoiding the relationship with the victim and punishment perceived by students were the most relevant factors leading to performance of cyberbullying, while remaining anonymous, power and having fun or boredom were secondary factors for performing cyberbullying, with differences between parents and teachers. Indeed, cyberbullying victims were most commonly those with a worse relationship with their parents and teachers compared to those who were not victims of cyberbullying (Bjereld, Daneback, \& Petzold, 2017), despite parent and teachers being essential in helping to efficiently solve both conflicts (Bjereld et al., 2017; Mishna, 2004).

Regarding coping strategies for cyberbullying, Smith et al. (2008) and Tokunaga (2010) showed that the technical strategies used by centers were no different to those employed by students: blocking someone or a message, talking to an adult about a bullying situation, changing an account or telephone number (Giménez-Gualdo, 2015), and in terms of assertive strategies; dialogue with the bully and seeking help in the community (Caba \& 
López, 2013).

When examining the strategies indicated by families, Sawyer, Mishna, Pepler, and Wiener (2011) found that most parents provided their offspring with maladaptive strategies. Those parents who offered positive coping strategies possessed considerable emotional intelligence and accompanied them in discourse about the bullying situation to stop it. This helped to prevent future bullying situations by providing strategies to defend oneself or for students to learn to maintain healthy social peer relationships (Sawyer et al., 2011; Schroeder, Morris, \& Flack, 2017).

It was interesting to note that those parents who suffered bullying when they were young better accompanied their offspring, provided their children with better strategies and paid more attention to these situations so they did not take place at all or become reiterative (Cooper \& Nickerson, 2013; Sawyer et al., 2011). However, Cooper and Nickerson (2013) indicated that cyberbullying was a new type of bullying for families who did not grow up with it. This perhaps relates to youths' possible motivation to share and make public cyberbullying cases rather than tell parents or teachers about it (Giménez-Gualdo, 2015).

\section{OBJECTIVES}

The present research arises from an interest in comparing teachers, students and families' perceptions, knowledge and coping strategies for cyberbullying. Bjereld et al. (2017) and Compton et al. (2014) conclude that this different perception is a problem that prevents progress being made in conflict resolution. Therefore, to overcome the limitations of previous studies (Lucas-Molina et al., 2016; Patchin \& Hinduja, 2006; Thomas et al., 2015) that employed different data collection instruments, we used the same questionnaire to collect data from students, teachers and families to investigate if differences existed in their perception of: a) the definition, typology and relevance of the roles involved in cyberbullying; b) the possible causes of cyberbullying; c) the use of different coping strategies for this phenomenon.

\section{METHODS}

\subsection{Sample}

The study sample (incidental for its accessibility) consisted of 116 participants from a school in the Spanish city of Zaragoza, and included students, families and teachers as follows: $51 \%$ were year- 6 Primary Education students $(n=59): 42.37 \%$ were male $(n=25)$ and $56.63 \%$ were female $(n=34) ; 29 \%$ were the participating students' family members $(n=34)$, mainly mothers $(76.5 \% ; n=24)$ when compared with fathers $(23.5 \%$; $=10)$, whose age range was $37-52$ years $(M=44.88 ; \mathrm{SD}=3.335)$; $20 \%$ were teachers from the school $(\mathrm{n}=23)$, with $21.74 \%$ males $(\mathrm{n}=5)$ and $78.26 \%$ females $(\mathrm{n}=18)$ and an age range of $38-64$ years $(\mathrm{M}=53.87 ; \mathrm{SD}=6.697)$, who taught different Primary Education years. 
To select the subsample corresponding to students, we chose year-6 Primary Education students according to the recommendations of Lucas-Molina et al. (2016), who found that this phenomenon was more marked for this Primary Education year and recommended conducting more cyberbullying research with this age group. For the families' subsample, we chose the parents of these students given their proximity to cyberbullying through their children. To form the teachers' subsample, we decided that we could select any Primary Education teacher regardless of the year they taught because they would be familiar with and know this phenomenon.

\subsection{Instrument}

We administered the same battery of questions to all the participants in a single ad hoc questionnaire, which we used to ask participants for the necessary information, which was as brief and efficient as possible in accordance with the variables we measured (García \& Alvarado, 2000). To validate the questionnaire's content, we sent its first version to four independent experts in the fields of education, co-existence, bullying and cyberbullying. We asked them to make an assessment according to four criteria (comprehension, suitability, relevance and format). They made an assessment on a 4-point Likert scale and could make suggestions to improve the questionnaire.

The kappa values for their observed agreements were suitable for all four criteria, which indicates that the experts agreed on the comprehensibility $(k=.875)$, suitability $(k=.931)$ and relevance $(k=.977)$ of the questions posed to assess the considered cyberbullying elements and the response format $(k=.869)$. We took into account the qualitative remarks that each judge made to improve the instrument and we made changes to the instrument to ensure the best possible validity. The final version did not change substantially from the initial version, and we included only some adaptations to the formulation of some items as improvements to make the questionnaire more accessible to year-6 Primary Education students. We also combined two items to form a single new one.

The questionnaire's final version started with a question to measure the independent variable: people's roles (students, family members and teachers), followed by five blocks of questions, one for each dependent variable as follows: a) knowledge about the definition and characteristics of cyberbullying; b) knowledge about the possible typologies or manifestations of cyberbullying; c) relevance of the roles involved in solving it; d) perception of the possible causes of cyberbullying; e) preferences towards coping strategies for cyberbullying.

To measure the variable "knowledge", we presented four possible definitions of cyberbullying. The participants had to select the correct one. Only one was valid. For the variable "typology", we presented different examples of cyberbullying manifestations. The participants had to identify if they were cyberbullying types or not. For the other variables, we provided different items for the participants to assess on a 4-point Likert scale according to the importance they attached to each one, ranging from 1: not very important to 4 : very important. 


\subsection{Procedure}

To conduct this study, given its accessibility, we contacted a school in the Spanish city of Zaragoza. After holding a meeting and obtaining the school management's approval, we informed all the teaching staff and contacted families by sending an informative letter. This letter explained what the research study consisted of and the use of the questionnaire, and requested authorization for both parents and their children to participate. According to research ethics, we provided information on and guaranteed correct data collection processing and maintaining anonymity of response by means of the informed consent collected from the participants.

We administered the questionnaire mainly during face-to-face sessions, supervised by one research team member. With the school children, we collected data in each classroom that corresponded to one of the year-6 Primary Education groups during a morning session. The session during which we administered the questionnaire with each group lasted $30 \mathrm{~min}$ utes. We administered the questionnaire to teachers during another 30-minute session, held when the school day had ended. Once again, one research team member supervised this session. With families, to help their participation and to adapt to their availability, we offered them two options: i) a face-to-face 30-minute session at the end of the day, supervised by the research team; ii) completing a printed questionnaire independently at home.

\subsection{Data analysis}

The intention of this selective correlational and cross-sectional study was to analyze the relationships among different dependent variables in diverse population groups (students, teachers, families). We carried out descriptive data analyses and tests to assess the significance of the differences among groups. We used the SPSS software (22.0.0) of IBM Corp. (2013) to perform the data analyses.

We ran Chi squared $(\chi 2)$ tests for the qualitative variables to measure the power of the relationships among the variables. After using Kolmogorov-Smirnov significance tests (with Lilliefors correction), the normality criterion was not met in any case for the quantitative variables $(\mathrm{p}<.000)$, and we ran non-parametric tests (Kruskal-Wallis) to compare the differences in the means among our independent samples.

\section{RESULTS}

\subsection{Knowledge about defining cyberbullying}

For the four definitions we gave to the people answering the questionnaire (Table 1), and after carrying out the $\chi 2$ tests among the different groups, we found no significant differences among them. This result notwithstanding, we stress that both teachers and families were better able to identify the definition of this phenomenon $(69.6 \%$ and $67.6 \%$ correctly identified the definition, respectively), compared to students ( $50.8 \%$ of cases correctly identified the definition). 


\begin{tabular}{|c|c|c|c|c|c|c|}
\hline \multirow[t]{2}{*}{ Item } & \multicolumn{2}{|c|}{ Students } & \multicolumn{2}{|c|}{ Teachers } & \multicolumn{2}{|c|}{ Families } \\
\hline & $\mathrm{f}$ & $\%$ & $\mathrm{f}$ & $\%$ & $\mathrm{f}$ & $\%$ \\
\hline Without imbalance & 17 & $28.8 \%$ & 4 & $17.4 \%$ & 5 & $14.7 \%$ \\
\hline Correct & 30 & $50.8 \%$ & 16 & $69.6 \%$ & 23 & $67.6 \%$ \\
\hline Without violence & 12 & $20.3 \%$ & 3 & $13,00 \%$ & 5 & $14.7 \%$ \\
\hline WV-WR-WI & 0 & $0 \%$ & 0 & 0 & 1 & $2.9 \%$ \\
\hline Total & 59 & $100.00 \%$ & 23 & $100.00 \%$ & 34 & $100.00 \%$ \\
\hline
\end{tabular}

Note: WV-WR-WI = Without Violence, Without Repetition, Without Imbalance

\subsection{Identifying different cyberbullying typologies}

First, it is worth mentioning that, except for item 4 (disputed comment), all the items offered brief examples of possible correct cyberbullying types (Table 2). After running the $\chi^{2}$ tests among the different groups, we obtained the following significant results.

\begin{tabular}{lcccccc}
\hline \multicolumn{7}{l}{ Table 2 Percentage of success in identifying types of cyberbullying } \\
Item
\end{tabular}

Significant differences appeared between students and families for item 1 (social exclusion; $\chi^{2}=6.612 ; \mathrm{p}=0.01$ ). Students' knowledge was significantly poorer, although none of the three groups obtained positive results for this item and all their scores were below $50 \%$ for right answers. Once again, we obtained significant differences for item 2 (denigration) between students and families $\left(\chi^{2}=5.514 ; \mathrm{p}=0.019\right)$, and families better identified it.

Interestingly, we noted significant differences for the other items between students and the other two groups, and inversely to that previously found; i.e. for item 3 (harassment), this cyberbullying type was identified significantly better by students than by teachers $\left(\chi^{2}=\right.$ 13.923; $\mathrm{p}=0.00)$ and families $\left(\chi^{2}=11.824 ; \mathrm{p}=0.01\right)$. No significant differences were found between teachers and families (50\% did not correctly answer).

The same occurred with item 5 (impersonating identity), with significant differences between students and teachers $\left(\chi^{2}=5.761 ; \mathrm{p}=0.016\right)$, and between students and families $\left(\chi^{2}=3.944 ; \mathrm{p}=0.047\right)$. On this occasion, however, the three groups correctly answered more than $70 \%$ of the items, and $93.2 \%$ of the students correctly answered. Finally, significant differences appeared for item 6 (happy slapping) between students and teachers $\left(\chi^{2}=\right.$ 
$4.031 ; \mathrm{p}=0.045)$

\subsection{Relevance of the different roles in cyberbullying}

Every item in this block (Table 3) corresponded to one of the possible roles played in cyberbullying dynamics, which the participants had to assess on a 4-point Likert scale (the higher the scores, the more importance they attached). First, in descriptive terms, we stress that students perceived the victim $(M=3.58 ; S D=.951)$ and defender spectator $(M=3.59 ; S T$ $=.833$ ) roles as more important for solving cyberbullying. Conversely, they attached less importance to the non-involved spectator role $(M=1.86$; $S D=.937)$, followed by possible defender spectator $(M=2.32 ; S D=.918)$. Like students, teachers perceived the defender spectator $(M=3.78 ; S D=.518)$ and victim $(M=3.78 ; S D=.518)$ roles as more important. These data contrast with the results obtained by families, who believed that the involved supporter $(M=3.53 ; S D=.748)$ and bully $(M=3.50 ; S D=.896)$ roles were more important and were those to variables to be worked on.

Table 3 Mean, standard deviations and Kruskal-Wallis test for independent samples of the relevance of roles against cyberbullying

\begin{tabular}{|c|c|c|c|c|c|c|c|c|}
\hline \multirow[t]{2}{*}{ Item } & \multicolumn{2}{|c|}{ Students } & \multicolumn{2}{|c|}{ Teachers } & \multicolumn{2}{|c|}{ Families } & \multirow[t]{2}{*}{$\mathbf{H}$} & \multirow[t]{2}{*}{$\mathbf{p}$} \\
\hline & $\mathrm{M}$ & $\mathrm{SD}$ & $\mathrm{M}$ & SD & M & $\mathrm{SD}$ & & \\
\hline RolC - Bully & 3.03 & 1.286 & 3.74 & .689 & 3.50 & .896 & 6.544 & .038 \\
\hline RolC - Involved supporter & 2.56 & .970 & 3.57 & .896 & 3.53 & .748 & 33.2 & $<.001$ \\
\hline RolC - Passive supporter & 2.42 & .986 & 3.39 & .891 & 3.24 & .741 & 22.977 & $<.001$ \\
\hline RolC - Victim & 3.58 & .951 & 3.78 & .518 & 3.12 & 1.225 & 5.708 & .058 \\
\hline RolC - Non-involved spectator & 1.86 & .937 & 3.17 & .778 & 2.82 & .758 & 34.897 & $<.001$ \\
\hline RolC - Defender spectator & 3.59 & .833 & 3.78 & .518 & 3.32 & .945 & 5.712 & .057 \\
\hline RolC - Possible defender spectator & 2.32 & .918 & 3.39 & .783 & 3.12 & .844 & 26.316 & $<.001$ \\
\hline
\end{tabular}

When we compared the results among groups, the following roles were significant: bully $\left(\chi^{2}=6.544 ; \mathrm{p}<.038\right)$, involved spectator $\left(\chi^{2}=33.20 ; \mathrm{p}<.001\right)$, passive spectator $\left(\chi^{2}=22.97\right.$; $\mathrm{p}<.001)$, non-involved spectator $\left(\chi^{2}=34.90 ;<=.001\right)$ and possible defender spectator $\left(\chi^{2}\right.$ $=26.316 ; \mathrm{p}<.001)$. In the pairwise comparisons, we found for the bully role that students totally disagreed with teachers $(\mathrm{p}<.049)$, who attached more importance to this role in terms of solving cyberbullying problems.

The results obtained when comparing all three groups for the importance they attached to involved supporter and passive supporter roles showed us that students disagreed with families $(\mathrm{p}<.001)$ and teachers $(\mathrm{p}<.001)$ because they attached less importance to these roles. The same happened with the non-involved spectator and the possible defender spectator roles because we found differences between students and both families $(\mathrm{p}<.001)$ and teachers $(\mathrm{p}<.001)$ because they attached less importance to these roles. Nonetheless, we observed no disagreement between teachers and families.

\subsection{Possible causes of cyberbullying}

In this questionnaire section, each item (Table 4) represents a possible cause of cyberbullying. In descriptive terms, students perceived that the most likely causes of this phenomenon 
were: remaining anonymous $(M=3.37 ; S D=.927)$ and it was easy to do $(M=3.20 ; S D=$ $.664)$. Boredom stood out as being the cause with the lowest score $(M=2.27 ; S D=1.014)$. All the other causes obtained scores between 2.8 and 3.0.

Table 4 Mean, standard deviations and Kruskal-Wallis test for independent samples of possible causes of cyberbullying

\begin{tabular}{|c|c|c|c|c|c|c|c|c|}
\hline \multirow{2}{*}{ Item } & \multicolumn{2}{|c|}{ Students } & \multicolumn{2}{|c|}{ Teachers } & \multicolumn{2}{|c|}{ Families } & \multirow[t]{2}{*}{$\mathbf{H}$} & \multirow[t]{2}{*}{$\mathbf{p}$} \\
\hline & M & $\mathrm{SD}$ & $\mathrm{M}$ & $\mathrm{SD}$ & $\mathrm{M}$ & $\mathrm{SD}$ & & \\
\hline For fun & 3.20 & .783 & 3.22 & .850 & 2.91 & .965 & 2.184 & .336 \\
\hline Boredom & 2.27 & 1.014 & 2.74 & .752 & 2.65 & .981 & 4.824 & .090 \\
\hline Improve your image on $\mathrm{SN}$ & 2.83 & .813 & 3.17 & .778 & 3.00 & 1.014 & 3.146 & .207 \\
\hline Take away popularity in $\mathrm{SN}$ & 3.03 & .787 & 3.09 & .793 & 3.15 & .958 & .867 & .648 \\
\hline Remove you from groups & 2.97 & .946 & 3.22 & .671 & 3.12 & .880 & 1.030 & .598 \\
\hline Avoid face to face confrontation & 3.12 & .984 & 3.13 & .815 & 3.24 & .819 & .264 & .877 \\
\hline Easy to do & 3.20 & .664 & 3.35 & .647 & 3.44 & .705 & 3.311 & .191 \\
\hline Remain anonymous & 3.37 & .927 & 3.61 & .583 & 3.41 & .783 & .700 & .705 \\
\hline Avoid penalty & 2.81 & 1.074 & 3.22 & .795 & 3.06 & .952 & 2.416 & .299 \\
\hline
\end{tabular}

The teacher group perceived the most likely causes behind cyberbullying to be remaining anonymous $(M=3.61 ; S D=.583)$ and easy to do $(M=3.35 ; S D=.647)$, which matched the views of students. Teachers also agreed with the lowest-scored cause, boredom $(M=$ 2.74; $S D=.752$ ). Families emphasized the same most likely causes, but in reverse order of importance compared to the other two groups, by giving a higher mean score to easy to do $(M=3.44 ; S D=.705)$ than remaining anonymous $(M=3.41 ; S D=.783)$. Boredom ( $M=2.65 ; S D=.981)$ was once again the least likely cause for families. It is noteworthy that no inter-group comparison was significant, which indicates that there were no striking discrepancies among the three groups for the causes of this phenomenon.

\subsection{Coping strategies for cyberbullying}

In this last block, each item (Table 5) represents a possible coping strategy for cyberbullying. Students perceived the following two coping strategies as the most effective: tell a family member $(M=3.63 ; S D=.692)$ and block $(M=3.27 ; S D=.762)$, but scored the next strategy as the least effective: post the cyberbullying action in social networks and do not tell parents about it $(M=2.08 ; S D=.970)$.

Teachers perceived the best strategies to be tell a family member $(M=3.74 ; S D=.449)$ and tell a teacher $(M=3.65 ; S D=.487)$, and the least effective strategy to be post the cyberbullying action in social networks and do not tell parents about it $(M=1.43 ; S D=.507)$, with quite a large difference. Families placed the highest value on the strategies tell a family member ( $M$ $=3.71 ; S D=.719)$ and tell a teacher $(M=3.65 ; S D=.734)$, and perceived the lest effective strategy to be post the cyberbullying action in social networks and do not tell parents about it $(M=1.32 ; S D=.684)$.

After comparing strategies per group, we found significant differences only for two strategies: change telephone number $\left(\chi^{2}=6.69 \mathrm{p}=.035\right)$ and post the cyberbullying action in social networks and do not tell parents about it $\left(\chi^{2}=19.50 \mathrm{p}<.001\right)$. For the strategy change 
Table 5 Mean, standard deviations and Kruskal-Wallis test for independent samples of cyberbullying coping strategies

\begin{tabular}{|c|c|c|c|c|c|c|c|c|}
\hline \multirow[t]{2}{*}{ Item } & \multicolumn{2}{|c|}{ Students } & \multicolumn{2}{|c|}{ Teachers } & \multicolumn{2}{|c|}{ Families } & \multirow[t]{2}{*}{$\mathbf{H}$} & \multirow[t]{2}{*}{$\mathbf{p}$} \\
\hline & M & SD & M & SD & $\mathrm{M}$ & SD & & \\
\hline Block & 3.27 & .762 & 3.04 & 1.022 & 2.91 & 1.111 & 1.789 & .409 \\
\hline Tell a teacher & 3.27 & .925 & 3.65 & .487 & 3.65 & .734 & 5.932 & .052 \\
\hline Tell a family member & 3.63 & .692 & 3.74 & .449 & 3.71 & .719 & .861 & .650 \\
\hline Dialogue with the bully & 2.53 & 1.006 & 2.87 & .968 & 2.88 & .977 & 3.633 & .163 \\
\hline Seek help in the SN group & 2.95 & .899 & 3.26 & .752 & 3.06 & .886 & 2.158 & .340 \\
\hline Change email and passwords & 2.80 & .924 & 2.43 & .843 & 2.35 & 1.125 & 4.865 & .088 \\
\hline Change telephone number & 2.63 & 1.065 & 2.30 & .703 & 2.09 & .965 & 6.692 & .035 \\
\hline Post the cyberbullying action in $\mathrm{SN}$ and do not tell parents & 2.08 & .970 & 1.43 & .507 & 1.32 & .684 & 19.503 & $<.001$ \\
\hline
\end{tabular}

telephone number, a disagreement appeared for the pairwise comparison between families and students $(\mathrm{p}=.034)$ as students perceived it to be very useful.

Although teachers scored this strategy poorly, as did families, the data reflected that this score was not significant compared to the data obtained for students. Finally, families (family members-students $\mathrm{p}<.001$ ) and teachers (teachers-students; $\mathrm{p}=.023$ ) perceived the strategy post the cyberbullying action in social networks and do not tell parents about it as the worst possible one, and gave it a significantly lower mean score than students did, even though students also perceived this strategy to be the least effective, but not as intensely.

\section{DISCUSSION}

Our primary research objective was to find out if there were differences in how students, teachers and families perceived the definition, typology and roles involved in cyberbullying. We began by identifying their definition. In contrast to the findings of Compton et al. (2014), our teachers did not ignore the intentionality characteristic, and students perceived that reiteration was the defining factor.

These differences may be due to research studies employing distinct data collection formats, as mentioned by Lucas-Molina et al. (2016), Patchin and Hinduja (2015) and Thomas et al. (2015) in their studies. Inclusion or non-inclusion of the definition of the phenomenon in an instrument can prove a key factor for finding differences, as could have been the case with the research by Compton et al. (2014). These authors did not provide those answering the questionnaire with a definition at any time. Despite not observing any significant differences in our work, it was noteworthy that students were less able to identify the cyberbullying definition (50.8\% answered correctly) compared to teachers (69.6\%) and families (67.6\%).

When identifying the different cyberbullying typologies, it was remarkable that the item referring to social exclusion obtained extremely low percentages of right answers. We also stress that another item led to worrying scores; harassment on networks, for which $80 \%$ of students answered correctly, while families and teachers did not exceed 50\%. 
When considering the roles set out by Sánchez and Cerezo (2011) for the bullying/cyberbullying phenomena, the importance of these roles in solving cybercullying cases differed across the three groups. It is noteworthy that both families and teachers attached more relevance to all the roles involved to overcome the phenomena, unlike students, who were the only group to have perceived passive roles like non-involved spectator and passive spectator as less relevant.

This finding contradicts the statements made by Thomas et al. (2015), whose work highlighted the relevance of all roles to overcome cyberbullying by stressing that spectators of any kind were very important roles for defending the victim or stopping the bully. The differences between teachers and families essentially lay in the victim and defender spectator roles because families gave lower scores than teachers and students, but higher scores for the bully and involved spectator roles.

In relation to our second research objective, and bearing in mind what other studies have evidenced Compton et al. (2014), we expected to find differences in how cyberbullying causes were perceived. In line with the results of Compton et al. (2014), families and teachers agreed that remaining anonymous and easy to do were the most likely causes for performing cyberbullying. Conversely, students perceived the causes avoiding the bully and punishment to be more likely. It is worth mentioning that differences were found in the order of selecting the possible causes, but they were not significant when comparing all three groups to one another.

Based on former studies (Cooper \& Nickerson, 2013; Giménez-Gualdo, 2015; Ozansoy, Altınay, \& Altınay, 2018), we expected to find significant differences for our last research objective: use of coping strategies to face cyberbullying. Unlike the results of Ozansoy et al. (2018), which indicated that schools tended to favour technical strategies, both the teachers and families in our sample perceived three of the four presented proactive strategies as the most suitable ones, which were tell a teacher, tell a family member and seek help in the social network group, which were the most suitable ones according to Caba and López (2013) and Giménez-Gualdo (2015), but avoided technical-type strategies.

Contrary to the results of Cooper and Nickerson (2013), the surveyed families positively scored conflict-resolution strategies. We stress that, once again, students differed from the other two groups in terms of strategies for preventing and facing cyberbullying, as they opted for the strategies change telephone number and post the cyberbullying action in social networks and do not tell parents about it because they attached more relevance to them. In Giménez-Gualdo (2015) study, students preferred to post the cyberbullying action in social networks and do not tell parents about it, whereas our students gave a low score for this option as a possible means for solving cases of cyberbullying.

The fact that we found no significant differences between teachers and families suggests a better than expected understanding between these parties in relation to suitably resolving cyberbullying-type conflicts. This was not the only very positive fact because all our groups perceived the strategies tell a teacher and tell a family member to be very valid, albeit to a lesser extent with students. 
We also highlight the fact that, although students attached less importance to technical strategies, unlike Smith et al. (2008), this group gave them the highest score. Finally, we saw no significant differences among the three groups for one strategy, but it received a higher score than anticipated: block the bully. This strategy proved particularly useful for all three groups (for students to the greatest extent). However, it has been posited that this strategy would not solve a cyberbullying case in some contexts or situations, and could even make it worse (Tokunaga, 2010).

\section{LIMITATIONS AND CONCLUSIONS}

This study is not without its limitations, which affect the sample selection process and the possibilities of generalizing its results. Our incidental selection of a school given its accessibility is a major limitation for generalizing the present research results. Although the student-teacher participation rate was quite high, we cannot say the same for students' families who, for various reasons (e.g., work, lack of availability) had a low participation rate despite us facilitating the procedure to access and complete the questionnaire. We expected the number of families to come close to the number of participating students ( $80 \%$ of all the year-6 students).

Bearing in mind that one strong feature of the present research was use of the same instrument - validated by a group of experts beforehand - with all the participants, employing a closed questionnaire could influence participants' responses and eliminate the possibility of them mentioning other causes and coping strategies that we may not have contemplated. It would be interesting to conduct future work with more flexible data collection methodologies to overcome the inflexibility of closed questionnaires. The fact that a percentage of the families completed the questionnaire at home with no supervision could also act as a limitation, given the lack of control of the process followed in collecting these participants' data.

Briefly, despite these limitations, our study results contribute to current cyberbullying research, but it is essential to attach importance to preventing, training in and, in short, dealing with cyberbullying at schools. Just as different co-existence projects have been set up to address harassment at many schools, we should start implementing specific actions regarding cyberbullying with validated programs such as Asegúrate (Rey, Ortega-Ruiz, \& Casas, 2019) or ConRed (Ruiz, Alamillo, \& Bolaños, 2012) to provide students with new skills and knowledge as, despite knowing what they are facing, they need to completely understand it and directly address it.

In order to increase prevention and action against cyberbullying, it will be necessary not only to look more profoundly at the role played by teachers and families by promoting training programs to increase their knowledge, but also to implement new ones to train them in suitable coping strategies. One such example is RPC (Guarini, Menin, Menabò, \& Brighi, 2019), which has helped to provide teachers and families with the physical and emotional tools they need to fight cyberbullying and to efficiently help students and their children. 
This study intended to look closely at the differences among three groups of people in their knowledge and capacity to face cyberbullying. Our results reflect different views for all three groups, which were significant despite using the same instrument to measure each variable, except when referring to causes. Thus, it is worth engaging these three groups simultaneously in future research to focus mainly on identifying cyberbullying, knowing the relevance of the involved groups in solving it and, above all, coordinating the strategies provided by families and teachers to students with training programs or new collective work tools.

\section{REFERENCES}

Bjereld, Y., Daneback, K., \& Petzold, M. (2017). Do bullied children have poor relationships with their parents and teachers? A cross-sectional study of Swedish children. Children and Youth Services Review, 73, 347-351. tps://doi.org/10.1016/j.childyouth.2017.01.012

Caba, M. A. D. L., \& López, R. (2013). La agresión entre iguales en la era digital: estrategias de afrontamiento de los estudian-tes de último ciclo de Primaria y del primero de Secundaria. Revista de Educación, 362, 247-272. https://doi.org/10-4438/1988-592X-RE-2011-362-160

Cerezo, F. (2009). La violencia en las aulas: análisis y propuestas de intervención. Madrid: Pirámide.

Chan, H. C. O., \& Wong, D. S. (2017). Coping with cyberbully-ing victimization: An exploratory study of Chinese adoles-cents in Hong Kong. International Journal of Law, Crime and Justice, 50(1), 71-82. https://doi.org/10.1016/j.ijlcj.2017.04.003

Compton, L., Campbell, M. A., \& Mergler, A. (2014). Teacher, parent and student perceptions of the motives of cyberbullies. Social Psychology of Education, 17(3), 383-400. https://doi.org/ 10.1007/s11218-014-9254-x

Cooper, L. A., \& Nickerson, A. B. (2013). Parent Retrospective Recollections of Bullying and Current Views, Concerns, and Strategies to Cope with Children's Bullying. Journal of Child and Family Studies, 22(4), 526-540. https://doi.org/10.1007/s10826-012-9606-0

Cowie, H. (2013). Cyberbullying and its impact on young people's emotional health and well-being. The Psychiatrist, 37, 167-170. https://doi.org/10.1192/pb.bp.112.040840

García, M. V., \& Alvarado, J. M. (2000). Métodos de investigación científica en psicología. Experimental, selectivo, observacional. Barcelona: EUB.

García-Fernández, C. M., Romera-Félix, E. M., \& Ortega-Ruiz, R. (2016). Relaciones entre el bullying y el cyberbullying: prevalencia y co-ocurrencia. Pensamiento Psicológico, 14, 49-61. https://doi.org/10.11144/javerianacali.ppsi14-1.rbcp

Giménez-Gualdo, A. M. (2015). Estrategias de afrontamiento ante el cyberbullying. Un acercamiento cualitativo desde la perspectiva de los escolares. Fronteiras: Journal of Social, Technological and Environmental Science, 3(3), 15-15. https://doi.org/10.21664/2238-8869.2014v3i3 .p15-32

Guarini, A., Menin, D., Menabò, L., \& Brighi, A. (2019). RPC Teacher-Based Program for Improving Coping Strategies to Deal with Cyberbullying. International Journal of Environmental Research and Public Health, 16(6), 948-948. https://doi.org/10.3390/ijerph16060948

Kowalski, R. M., \& Limber, S. P. (2007). Electronic Bullying Among Middle School Students. Journal of Adolescent Health, 41(6), S22-S30. https://doi.org/10.1016/j.jadohealth.2007.08.017

Lazarus, R. S. (1993). Coping theory and research: past, present, and future. Psychosomatic Medicine, 55(3), 234-247. https://doi.org/10.1097/00006842-199305000-00002

Lucas-Molina, B., Pérez-Albéniz, A., \& Giménez-Dasí, M. (2016). La evaluación del cyberbullying situación actual y retos futuros. Papeles del psicólogo, 37(1), 27-35. 
Menesini, E., Nocentini, A., \& Calussi, P. (2011). The Measurement of Cyberbullying: Dimensional Structure and Relative Item Severity and Discrimination. Cyberpsychology, Behavior, and Social Networking, 14(5), 267-274. https://doi.org/10.1089/cyber.2010.0002

Mishna, F. (2004). A Qualitative Study of Bullying from Multiple Perspectives. Children \& Schools, 26(4), 234-247. https://doi.org/10.1093/cs/26.4.234

Mudhovozi, P. (2015). Bullies and Victims at a Public Secondary School:. International Journal of Educational Sciences, 10(1), 115-121. https://doi.org/10.1080/09751122.2015.11890348

Olweus, D. (1993). Bullying at School: What We Know \& What We Can Do. United Kingdom: Blackwell Publishers. https://doi.org/10.1002/pits.10114

Ortega-Ruiz, R., \& Zych, I. (2016). La ciberconducta y la psicología educativa: retos y riesgos. Psicología Educativa, 22, 1-4. https://doi.org/10.1016/j.pse.2016.04.001

Ozansoy, K., Altınay, Z., \& Altınay, F. (2018). Developing Strategies to Prevent "Cyber-Bullying”. EURASIA Journal of Mathematics, Science and Technology Education, 14(5), 1925-1929. Retrieved from https://doi.org/10.29333/ejmste/85499 10.29333/ejmste/85499

Patchin, J. W., \& Hinduja, S. (2006). Bullies Move Beyond the Schoolyard. Youth Violence and Juvenile Justice, 4, 148-169. https://doi.org/10.1177/1541204006286288

Patchin, J. W., \& Hinduja, S. (2015). Measuring cyberbullying: Implications for research. Aggression and Violent Behavior, 23, 69-74. https://doi.org/10.1016/j.avb.2015.05.013

Rey, R. D., Ortega-Ruiz, R., \& Casas, J. (2019). Asegúrate: An Intervention Program against Cyberbullying Based on Teachers' Commitment and on Design of Its Instructional Materials. International Journal of Environmental Research and Public Health, 16(3), 434-434. https://doi.org/10.3390/ijerph16030434

Ruiz, R. O., Alamillo, R. D. R., \& Bolaños, J. A. C. (2012). Knowing, building and living together on internet and social networks: The ConRed cyberbullying prevention pro-gram. International Journal of Conflict and Violence, 6(2), 302-312. https://doi.org/10.4119/ijcv-2921

Sánchez, C., \& Cerezo, F. (2011). Bullying y cyberbullying: investigación e intervención en contextos escolares y socia-les. Revista Española de Orientación y Psicopedagogía, 22(2), 137-149.

Sawyer, J.-L., Mishna, F., Pepler, D., \& Wiener, J. (2011). The missing voice: Parents' perspectives of bullying. Children and Youth Services Review, 33(10), 1795-1803. https://doi.org/10.1016/ j.childyouth.2011.05.010

Schenk, A. M., \& Fremouw, W. J. (2012). Prevalence, Psychological Impact, and Coping of Cyberbully Victims Among College Students. Journal of School Violence, 11(1), 21-37. https:// doi.org/10.1080/15388220.2011.630310

Schroeder, B., Morris, M., \& Flack, M. (2017). Exploring the relationship between personality and bullying; an investigation of parental perceptions. Personality and Individual Differences, 112, 144-149. https://doi.org/10.1016/j.paid.2017.02.066

Sittichai, R., \& Smith, P. K. (2018). Bullying and Cyberbullying in Thailand: Coping Strategies and Relation to Age, Gender, Religion and Victim Status. Journal of New Approaches in Educational Research, 7(1), 24-30. https://doi.org/10.7821/naer.2018.1.254

Smith, P. K., Mahdavi, J., Carvalho, M., Fisher, S., Russell, S., \& Tippett, N. (2008). Cyberbullying: its nature and impact in secondary school pupils. Journal of Child Psychology and Psychiatry, 49(4), 376-385. https://doi.org/10.1111/j.1469-7610.2007.01846.x

Thomas, H. J., Connor, J. P., \& Scott, J. G. (2015). Integrating Traditional Bullying and Cyberbullying: Challenges of Definition and Measurement in Adolescents - a Review. Educational Psychology Review, 27(1), 135-152. https://doi.org/10.1007/s10648-014-9261-7

Tokunaga, R. S. (2010). Following you home from school: A critical review and synthesis of research on cyberbullying victimization. Computers in Human Behavior, 26(3), 277-287. https://doi .org/10.1016/j.chb.2009.11.014 
Undheim, A. M., Wallander, J., \& Sund, A. M. (2016). Coping Strategies and Associations With Depression Among 12- to 15-Year-Old Norwegian Adolescents Involved in Bullying. The Journal of Nervous and Mental Disease, 204, 274-279. https://doi.org/10.1097/nmd .0000000000000474

von Marées, N., \& Petermann, F. (2012). Cyberbullying: An increasing challenge for schools. School Psychology International, 33, 467-476. https://doi.org/10.1177/0143034312445241 